\title{
Lexical contribution to nonword-repetition effects: Evidence from event-related potentials
}

\author{
MICHAEL D. RUGG and MARGARET E. NAGY \\ University of St. Andrews, St. Andrews, Scotland
}

\begin{abstract}
Two experiments investigated the modulation of event-related potentials (ERPs) by the repetition of orthographically legal and illegal nonwords. In Experiment 1, subjects silently counted occasional words against a background of nonwords, a proportion of which were repetitions of an immediately preceding legal or illegal item. ERPs to repeated legal items showed a sustained, topographically diffuse, positive-going shift. In contrast, repeated illegal nonwords gave rise to ERPs showing a smaller and temporally more restricted positive-going modulation. In an attempt to equalize depth of processing across legal and illegal nonwords, subjects in Experiment 2 were required to count items containing a nonalphabetic character against the same background of nonword items. ERPs to repeated legal items showed a modulation similar to, although smaller than, that found in Experiment 1, but no effects of repetition were observed in the ERPs to the illegal nonwords. It was concluded that the effects of repeating nonwords, at least as manifested in concurrently recorded ERPs, differ as a consequence of whether items can access lexical memory, and that this is inconsistent with the attribution of such effects solely to the operation of episodic memory processes.
\end{abstract}

The beneficial effects of the prior presentation of a word on the efficiency with which the word is processed on a subsequent occasion have been described in numerous studies that employed identification (e.g., Feustel, Shiffrin, \& Salasoo, 1983; Jacoby \& Dallas, 1981; Morton, 1969; Murrell \& Morton, 1974) and speeded lexical decision (e.g., Dannenbring \& Briand, 1982; Forbach, Stanners, \& Hochhaus, 1974; Monsell, 1985; Scarborough, Cortese, \& Scarborough, 1977) tasks. A popular means of accounting for such repetition effects has been to assume that they result from temporary modifications to representations in lexical memory. For example, in the model developed by Morton $(1969,1979)$, the activation of a word's logogen, caused by a presentation of the word, has the effect of temporarily lowering the logogen's threshold, thus facilitating lexical access to that item for some time following its initial presentation. This type of explanation of repetition effects can be contrasted with an alternative view, which postulates that these effects arise not by a change in the state of some preexisting memory representation, but as a result of the formation and subsequent retrieval of the memory about an item's prior presentation (Feustel et al., 1983; Jacoby, 1983; Salasoo, Shiffrin, \& Feustel, 1985). The notion that repetition effects reflect the operation of a contextsensitive episodic memory system gains much of its credence from the finding that, in some circumstances, non-

This research was supported by the Mental Health Foundation and the Medical Research Council of the United Kingdom. We thank C. Le Surf for assistance with data collection in Experiment 1, and A. F. Healy and two anonymous referees for constructive comments on an earlier version of this paper. Send reprint requests to M. D. Rugg, MRC Cognitive Neuroscience Research Group, Psychological Laboratory, University of St. Andrews, St. Andrews, Fife KY16 9JU, United Kingdom. words give rise to repetition effects comparable in magnitude to those observed with words, in both identification (Feustel et al., 1983; Salasoo et al., 1985) and lexical decision (Dannenbring \& Briand, 1982; Monsell, 1985) tasks. Given the plausible assumption that nonwords do not possess preexisting representations in lexical memory, these findings appear to indicate that, at least to some degree, modification of such representations cannot be the only means by which letter strings benefit from prior presentation. It is important, however, to note that nonword- and word-repetition effects differ in one important fashion: Whereas the facilitatory effects of word repetition on lexical decision performance persist for some time (up to 2 days in the case of the Scarborough et al., 1977 , study), they last for a considerably shorter time in the case of nonwords (Monsell, 1985). Although no comparable data currently exist in the case of identification tasks, it is worth noting that Johnston, Dark, and Jacoby (1985) reported less facilitation in the identification of nonwords than of words when these were repeated an unspecified number of minutes later. One can argue, therefore, that if an episodic component to repetition effects exists, it may, in comparison with lexically mediated processes, be relatively short-lived.

Notwithstanding the relatively short time intervals involved, it may be possible to account for nonwordrepetition effects without any recourse to nonlexical, episodic memory processes. Typically, the nonwords employed in such studies are pronounceable and orthographically legal. (In the studies of Feustel et al., 1983, and Salasoo et al., 1985, for example, the nonwords were constructed by changing only one letter of the words from which they were derived.) Such letter strings will necessarily contain familiar orthographic segments and also will 
be orthographically similar to one or more words. It is possible, therefore, that these items derive some benefit on repetition from persisting activation of the representations of sublexical orthographic units, and/or from the partial activation of the representations of orthographically similar words (cf. Evett \& Humphreys, 1981). Indeed, analogy models of reading aloud (e.g., Kay, 1985) explicitly assume that nonwords activate lexical representations. In either case, the locus of nonword-repetition effects would be largely within the lexical memory system.

Although almost all studies investigating repetition effects have employed behavioral measures, the current study and two previous studies (Rugg, 1985, 1987) employed scalp-recorded, event-related potentials (ERPs) as dependent variables. ERPs are event- or stimulus-locked perturbations of the EEG (the spontaneous electrical activity of the brain), recorded from electrodes on the scalp and usually separated from background activity by averaging (see Picton, 1980, for an introduction to the technique). ERPs consist of waveforms that represent changes in voltage over time and give a partial record of the neural processes set in train by stimulus presentation. The waveforms result from the summation of electrical activity propagated to the scalp from neural generators within the brain, the locations of which are mostly unknown and whose activities may overlap in time to a considerable extent. Conventionally, the deflections or "peaks" in an ERP waveform are labeled by their polarity and either their approximate latency or ordinal position. For example, P100 would be a positive peak with a latency around $100 \mathrm{msec}$; 2 would be the second negative peak in a waveform. Such features of ERPs are frequently referred to as components, and often have a characteristic amplitude distribution over the scalp, presumably because of the different spatial locations within the brain of their respective generators. Such topographic information can be an important means of distinguishing between components, particularly those that overlap in time, and it is customary to record ERPs from a variety of scalp sites for this purpose.

It is common to distinguish between exogenous and endogenous ERP components. Exogenous components are those generated in an obligatory fashion following the presentation of a stimulus, and they are present in the waveform largely irrespective of the subject's cognitive state. In contrast, endogenous components are not generated simply as a result of the presentation of a stimulus, but as a consequence of the engagement of stimulus-locked cognitive processes, contingent on such factors as task instructions, prior expectancies, and so forth. These components may modulate the regions of a waveform that contain more than one exogenous component, and they can have the effect of producing a general shift in polarity (compared to some other condition) of hundreds of milliseconds. One of the most pervasive and heavily researched endogenous components is the P3 component (also often known as the $\mathrm{P} 300$ or the late positive component; see
Pritchard, 1981, for an extensive review). This parietally distributed component is highly sensitive to factors such as stimulus probability and task relevance (DuncanJohnson \& Donchin, 1977), and it has a peak latency that appears to be correlated with the time taken to categorize eliciting stimuli (e.g., Coles, Gratton, Bashore, Eriksen, $\&$ Donchin, 1985). In view of the sensitivity of endogenous components such as P3 to stimulus probability, it is important that experiments intended to assess other aspects of the sensitivity of ERPs to some experimental manipulation be balanced with respect to the relative frequency of occurrence of their critical experimental conditions. For further details of the distinction between exogenous and endogenous components and their modulation in cognitive tasks, see Hillyard and Kutas (1983).

The real-time nature of ERPs and the fact that they can provide a virtually unobtrusive record of stimulus processing mean that they are an attractive means of complementing the behavioral analysis of information processing. They have become increasingly popular in this respect, particularly in studies of word recognition and related processes (Kutas \& Van Petten, 1987; Rugg, Kok, Barrett, \& Fischler, 1986). A series of reports by Kutas and Hillyard $(1980,1983,1984)$ is of particular relevance in the present context. These reports described a late negative ERP component (N400), the amplitude of which is related to the expectancy of the words eliciting it. When items in a sentence are sequentially presented, terminal words elicit an ERP with an N400 that is sensitive both to the words' cloze probability and to whether they are semantically related to a high-probability completion (Kutas \& Hillyard, 1984). This led Kutas and Hillyard to propose that the amplitude of $\mathrm{N} 400$ is inversely proportional to the degree to which a word has been semantically primed by prior context. A study of single-word priming in a lexical decision task (Bentin, McCarthy, \& Wood, 1985) is consistent with this proposal. Bentin et al. reported that $\mathrm{N} 400$ was attenuated in ERPs that were elicited by semantically primed targets in comparison with primes or control items.

If the effects of word repetition result largely from the processes that also underlie semantic priming, it might be expected that repeated words, like semantically primed items, would show an attenuation of N400. This was the reasoning behind Rugg's (1985) study, which investigated the effects on word-related ERPs of repeating or semantically priming items during a lexical decision task. As in the case of Bentin et al.'s (1985) study, semantically primed items gave rise to ERPs that contained a smaller N400 component than did primes or controls. ERPs from repeated words showed a larger and more sustained positive-going shift. The shift had a widespread scalp distribution, but it was difficult to separate this from a prominent, parietally distributed P3 component, the latency of which was shortened in this condition compared with the others. The shortened latency made it impossible to de- 
termine whether repetition and semantic priming modulated earlier regions of ERPs in qualitatively different fashions.

Rugg (1987) adopted a paradigm in which ERP repetition effects could be studied with items to which no overt response was required, but which were nonetheless subject to an implicit lexical decision. Subjects silently counted the occasional occurrence of nonwords, interspersed among a series of words, in which there were embedded repeats of the immediately preceding word. As in Rugg's (1985) study, ERPs to repeated items showed a sustained positive shift in comparison with controls, in contrast to a smaller, more short-lived and differently distributed modulation of ERPs from an equal proportion of words preceded by a strong semantic associate (the scalp topography of neither of these effects resembled previously reported ERP modulations interpreted as changes in the amplitude of $\mathrm{N} 400$ or P3 components). Rugg concluded that word repetition is a potent modulator of ERPs, and, on the basis of the qualitative and quantitative differences between repetition and semantic priming, that the processes responsible for this modulation are to a large degree distinct from those that are sensitive to purely semantic relationships between consecutive items (a conclusion consistent with recent behavioral studies: Den Heyer, Goring, \& Dannenbring, 1985; Wilding, 1986). A second experiment investigated whether a similar pattern of ERP modulation would be found when nonwords were the crucial stimuli. In this case, subjects counted occasional words against a background of nonword items, some of which were repeated. These items also gave rise to a positive-going modulation of ERPs, but this effect was both smaller in magnitude and slower to develop than in the case of words. In both experiments, there was evidence of an early (approximately $200 \mathrm{msec}$ ), transient negative-going modulation of ERPs from repeated items, which perhaps reflected the prelexical detection of stimulus repetition. On the basis of these data, Rugg concluded that, even though the interval between repetitions was short $(2.8 \mathrm{sec})$, the ERP data suggested that the effects of repetition were more profound for items that possessed a preexisting representation in lexical memory. This conclusion is inconsistent with the idea that the effects of repetition, even over short intervals, are mediated entirely by nonlexical, episodic memory processes.

Although the data from Rugg's (1987) study suggest that word-related ERP repetition effects resulted, at least partially, from repeated access to preexisting memory representations, they do not address the question of why nonword repetition modulated ERPs. At least two alternatives are possible: (1) This modulation could result from or reflect access to currently activated lexical or sublexical structures, as discussed previously with respect to the effects of nonword repetition on behavioral measures. (2) Nonword ERP repetition effects could arise because of the formation and subsequent retrieval of an episodic memory of an item's first presentation, which is independent of lexical processes. One way to decide between these alternatives is to employ nonwords that differ with respect to their orthographic legality. If the modulation of ERPs by repetition principally reflects lexical processing, it should be more extensive for orthographically legal items, since these will give rise to greater levels of activation within the lexical system than will illegal stimuli. However, if these ERP effects result largely through the operation of episodic memories of prior presentations, such a result would not be expected, since the two classes of item should have equal access to the episodic system. The present experiments attempted to distinguish between these alternatives by employing legal and illegal nonwords in Rugg's (1987) paradigm.

\section{EXPERIMENT 1}

\section{Method}

Subjects. The subjects were 12 young adults, 6 of whom were female. All had normal or corrected-to-normal vision.

Stimuli. The critical stimuli consisted of two sets of letter strings. There were 100 legal items, constructed by changing one or two letters of four- to seven-letter English words, so as to form pronounceable, orthographically regular nonwords. The 100 illegal nonwords were formed by rearranging and sometimes changing the letters in members of a similar set of words so as to form unpronounceable, orthographically irregular items. The two sets of items, examples of which are shown in Table 1, were matched with respect to length (mean length of legal items $=4.6$ letters, $S D=0.6$; illegal items $=4.6$ letters, $S D=0.7$ ). In addition to these critical items, an additional 20 items, 10 of each type, were also constructed and employed as fillers. A final set of 80 items consisted of four- to seven-letter English words, which served as targets.

These items were used to form two lists, which differed as to which items were employed in the repetition condition. In List 1, 50 legal and 50 illegal items were randomly selected to be repeated, and the remainder were employed as unrepeated control items. This allocation of items to the repetition and control conditions was reversed in List 2 . Each list employed the same order of conditions, which consisted of the pseudorandom ordering of pairs of identical items (designated R1 for the first presentation and R2 for the second), control items, fillers, and target words. Each list, therefore, consisted of 400 items, 320 of which were nonwords and 300 of which were of experimental interest. A practice list of 20 items also was constructed.

The stimuli were presented at a moderate contrast in uppercase on a TV monitor. The display window subtended a visual angle of $2^{\circ} \times 0.5^{\circ}$. A fixation asterisk was present in the center of the window until $110 \mathrm{msec}$ before stimulus presentation; it returned $708 \mathrm{msec}$ after stimulus onset. Stimulus duration was $161 \mathrm{msec}$, and the interstimulus interval was $2.8 \mathrm{sec}$.

Procedure. After electrode application, the subjects were seated in front of the TV monitor in a sound-attenuated room. They were instructed to keep a silent running count of the number of words

Table 1

Examples of the Legal and Illegal Nonwords Employed as Control, R1, and R2 Items in Experiments 1 and 2

\begin{tabular}{llll}
\hline \multicolumn{2}{c}{ Legal } & \multicolumn{2}{c}{ Illegal } \\
\hline FICT & FLEAR & SKHRA & THDEJ \\
DULIT & DEET & NPMO & TBUA \\
FRIME & HEND & LSIA & RLFRO \\
BLOOT & LIRD & ETBTR & MSUOQ \\
CHILT & NIPER & AKDR & RRWSI \\
\hline
\end{tabular}


that they saw during each experimental run. They also were told that they would sometimes see repetitions of immediately preceding items, that although this was part of the experiment it called for no action on their part, and that they should concentrate on maintaining an accurate count. The subjects also were requested to avoid eye-movements during the interval when the asterisk was not on the screen and to maintain fixation within the display window during that time. Following the practice trials, the 400 items from one of the lists were presented in four blocks of 100 items. The words were counted in each block separately, and the subjects rested between blocks for as long as they wished. Lists 1 and 2 were alternated across subjects.

ERP recording. EEG was recorded with silver/silver chloride electrodes from $\mathrm{Fz}, \mathrm{Cz}$, and $\mathrm{Pz}$ (i.e., from frontal, central, and parietal midline sites) and from lateral temporal sites. The lateral electrodes were placed $75 \%$ of the distance from $\mathrm{Cz}$ to $\mathrm{T} 3$ on the left and to $\mathrm{T} 4$ on the right (T3 and T4 are situated $80 \%$ along the lines from $\mathrm{Cz}$ to the left and right preauricular points, respectively). All EEG electrodes were referred to linked mastoids. The electrooculogram (EOG) was recorded bipolarly between electrodes situated on the outer canthus of the left eye and just above the right eyebrow. EEG and EOG were recorded with a bandpass of $.03-30 \mathrm{~Hz}$ (3-dB points) and sampled on-line at a rate of $3 \mathrm{msec}$ per point, starting $60 \mathrm{msec}$ before stimulus onset and continuing for 708 msec thereafter. Averaged ERPs were computed from each electrode for the legal and illegal control, R1, and R2 items. Trials on which blinks or other gross eye movements occurred (causing artifact in the EEG, especially over anterior scalp regions) were rejected automatically, and the EOG was averaged, so that the lack of stimulus-locked eye movements could be verified for each subject.

\section{Results}

Grand average waveforms elicited by the control, R1, and R2 legal and illegal items are illustrated in Figure 1. The mean number of trials included in individual subjects' averages for each condition was 44 , with a range of 33 to 50 . (This variation reflects the rejection of trials that contained EOG artifact.) N1 and $\mathrm{P} 2$ peaks are present in these waveforms at all sites. At the $\mathrm{Pz}$ electrode, there is evidence of a second positive peak with a latency around $300 \mathrm{msec}$. Following these peaks, the waveforms consist of a sustained slow wave with a posterior maximum and a largely symmetrical distribution across the temporal electrodes. The effects of repetition appear to take the form of a modulation of this latter region of the waveform and to be manifested as a sustained positive-going shift. This shift is larger in magnitude and temporally more extended in the ERPs elicited by the legal nonwords than in those elicited by the illegal nonwords. In addition, there is some sign, in the legal waveforms, of an earlier, more transient modulation, which takes the form of a negative-going effect in the region of the P2 component in the $\mathrm{R} 2$ waveforms.

These data were quantified by measuring, with respect to the mean of the prestimulus baseline, the mean amplitude of selected regions of subjects' waveforms. To preserve comparability with Rugg (1987), these encompassed the latency range of the early transient repetition effect (201225 msec, straddling the $P 2$ component and encompassing the apparent repetition effect in this latency region), and an early and late measure of the later, more sustained effect (300-399 and 402-600 msec, respectively; in the

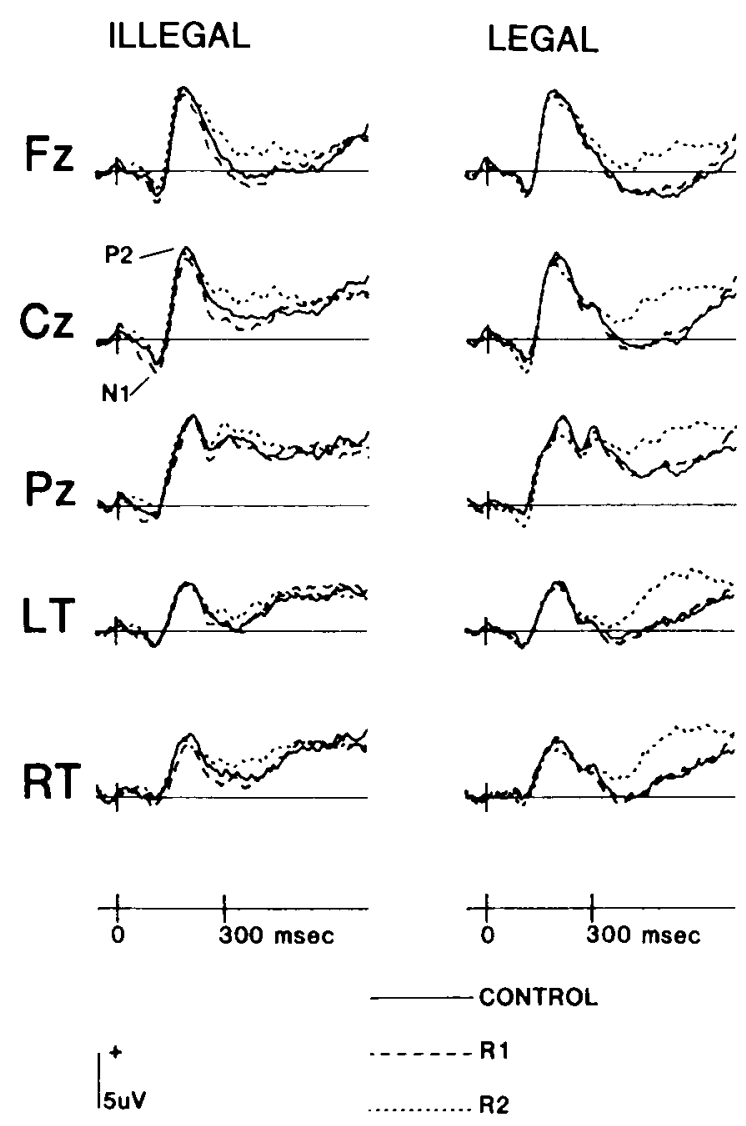

Figure 1. Grand average waveforms from Experiment 1, elicited by control, R1, and R2 orthographically illegal and legal nonwords. $\mathrm{Fz}, \mathrm{Cz}$, and $\mathrm{Pz}$ refer to frontal, central, and parietal midline electrodes. LT and RT signify left and right temporal electrodes. N1 and $\mathbf{P} 2$ components are indicated.

present study, the earlier measure encompasses a region of the waveforms in which the two types of stimuli appear to exhibit similar repetition effects, whereas repeated legal items appear to modulate the later region to a larger extent than illegal repeats). The $228-297 \mathrm{msec}$ interval was also measured in the present experiment, to allow an assessment of the reliability of the effects of repetition evident in this region of the waveform, particularly in the illegal condition. These data were evaluated using repeated measures ANOVAs with factors of stimulus type (legal/ illegal), repetition condition (control, R1, and R2), and electrode site. ${ }^{1}$ All $F$ ratios were tested using the Greenhouse-Geisser correction for nonhomogeneity of covariance in repeated measures designs (Keselman \& Rogan, 1980). The reliability of repetition effects on the two item classes was evaluated by planned comparisons between the measures derived from the $\mathrm{R} 1$ and $\mathrm{R} 2$ conditions. The degrees of freedom associated with the error terms employed in these comparisons were also adjusted by the application of the Greenhouse-Geisser correction, so as to correct for the bias introduced into these terms by departures in the data from the assumption of homogeneity of covariance.

Analysis of the 201-225 msec latency region gave rise to only one significant effect, that of electrode site 
$[F(2.4,26.7)=10.43, p<.0001, M S e=15.04]$, reflecting the larger midline amplitudes of this variable in comparison with those at the lateral sites. Planned comparisons of the R1 and R2 measures for the legal and illegal items revealed no significant effect in either case, indicating that the apparent early effect observable for the legal items in the grand averages (Figure 1) was not reliable.

The 228-297 msec data are shown in Table 2. As in the previous analysis, an ANOVA revealed a significant effect only for electrode site $[F(2.5,27.5)=7.2$, $p<.005, M S e=21.55]$. Planned comparisons of the $\mathrm{R} 1$ and $\mathrm{R} 2$ measures indicated no significant difference in the case of the legal items, but a reliable effect in the case of the illegal condition $[F(1,14.9)=5.49, p<.05$, $M S e=13.12]$. This reflected the greater magnitude of this measure in ERPs from repeated compared with those from unrepeated illegal items.

The 300-399 and 402-600 msec data are also shown in Table 2. Analysis of the first of these latency regions gave rise to significant effects of electrode site $[F(2.2,24.6)=9.88, p=.001, M S e=34.15]$, condition $[F(1.3,13.8)=7.49, p<.02, M S e=12.13]$, class of nonword $[F(1,11)=14.73, p<.005, M S \mathrm{e}=4.66]$, and interaction of this latter factor with electrode site $[F(2.7,29.7)=5.61, p=.005, M S e=0.68]$. Planned comparisons indicated that the $\mathrm{R} 1 / \mathrm{R} 2$ differences were significantly different for both legal $[F(1,13.8)=9.82]$ and illegal items $[F(1,13.8)=19.63]$. The main effect of item class was caused by the values of this measure being greater in the ERPs elicited by the illegal items. The interaction between this factor and electrode site reflected the smaller size of this effect at the Fz electrode site in comparison with the others.

Analysis of the $402-600$ msec region showed significant effects for electrode site $[F(2,22.2)=6.76, p=$ $.005, M S e=30.40]$, class of item $[F(1,11)=8.63$, $p<.02, M S \mathrm{e}=20.17]$, condition $[F(1.4,14.9)=10.57$, $p<.005, M S e=17.52]$, and class of item $\times$ condition interaction $[F(1.8,20)=5.96, p<.02, M S e=12.17]$. Planned comparisons indicated that the R1/R2 differences were highly reliable for the legal items $[F(1,14.9)=$ 39.43] but nonsignificant in the case of the illegal nonwords $[F(1,14.9)=1.07]$. In addition, post hoc analysis (Tukey's HSD) indicated that this region of the ERPs was more positive-going in the waveforms elicited by the ille-

Table 2

Mean Amplitude (Microvolts) Across Electrode Sites of the 228-297, 300-399, and 402-600 msec Regions of the Waveforms in Experiment 1

\begin{tabular}{clcccc}
\hline Region & Items & Control & R1 & R2 & R2-R1 \\
\hline $228-297 \mathrm{msec}$ & Legal & 3.98 & 3.71 & 3.87 & 0.16 \\
& Illegal & 3.81 & 2.96 & 4.51 & $1.55^{*}$ \\
$300-399 \mathrm{msec}$ & Legal & 1.45 & 1.05 & 2.46 & $1.41 \dagger$ \\
& Illegal & 2.27 & 1.66 & 3.65 & $1.99 \dagger$ \\
$402-600 \mathrm{msec}$ & Legal & 0.71 & 0.87 & 4.26 & $3.39 \dagger$ \\
& Illegal & 2.83 & 3.31 & 3.87 & 0.56 \\
\hline
\end{tabular}

${ }^{*} p<.05 . \quad \dagger p<.01$. gal compared with the legal items in the control and R1 conditions, but not in the R2 condition.

Eighty targets were presented over the course of the experiment. The mean number reported by subjects was $78(S D=5.4)$.

\section{Discussion}

The data from this experiment clearly indicate that the repetition of orthographically legal nonwords gives rise to a different pattern of modulation of concurrently recorded ERPs from that observed with the repetition of illegal items. In particular, later regions of the waveforms (post- $400 \mathrm{msec}$ ) showed a large and sustained positive shift in the case of repeated legal nonwords, and no reliable effect at all for illegal items. Their repetition gave rise instead to a somewhat smaller and earlier-occurring effect. One account of these results is that repetition effects differ between items that possess an orthographic structure allowing access to the lexical system and items that do not. Such an account would suggest that the nonword ERP repetition effects observed by Rugg (1987) reflected the operation of lexical as well as episodic memory mechanisms. More generally, it implies that the employment of nonword items may not by itself be a sufficient reason to implicate episodic processes when these items exhibit repetition effects (see Feustel et al., 1983; Salasoo et al., 1985).

There is, however, a difficulty in accepting that the results of this experiment indicate that, in general, repeated orthographically legal and illegal nonwords differ in the manner and potency with which they modulate ERPs. The task employed required the subjects to discriminate each item on the basis of whether or not it was a word. Although this discrimination would require a lexical search in the case of the legal nonwords, it would not with the illegal items, which could be classified as nonwords on the basis of orthographic features alone. Thus, these two classes of item could have differed with respect to their depths of processing, in which case the differential magnitude and time courses of their respective repetition effects might not simply be a property of their different orthographic structures. In support of this interpretation, it should be noted that the ERPs elicited by the control and R1 legal and illegal items differed from one another; the legal ERPs exhibited a relatively greater negativity in later regions of the waveform, which was attenuated by repetition. If this greater negativity is interpreted as in some way reflecting the more extensive processing of these items, then it is possible that its attenuation reflects the lesser degree of such processing that they are afforded on repetition; a degree similar to that required for illegal items even on their first presentations.

An additional problem in the interpretation of these results comes from a potential imbalance in the probabilities of the critical items. If subjects formed a subjective mental dichotomy between all orthographically legal items on the one hand and illegal items on the other (i.e., targets and legal nonwords vs. illegal nonwords), then ille- 
gal nonwords would, as a category, have the lower probability of occurrence. The probability of the subjective categories to which stimuli belong is known to be an important influence on the ERPs that they elicit, particularly with respect to the $\mathrm{P} 3$ component, which is larger to rarer items (Courchesne, Hillyard, \& Courchesne, 1977). It is possible, therefore, that this factor also contributed to the effects observed in the current study, in addition to the unequal processing demands of the two classes of item noted above.

Experiment 2 was conducted to resolve these difficulties with the interpretation of the results of Experiment 1. Instead of counting words, with the concomitant inequality of task demands across the two classes of nonwords, subjects were required instead to detect and keep a count of target items (half of which were legal nonwords, and half of which were illegal nonwords) containing a nonalphabetic character. It was assumed that this task would be no more difficult to perform with legal than with illegal nonwords, and thus that any residual differences in the ERP repetition effects shown by these items would be ascribable to their orthographic structures. One problem with this procedure is that it neither demands nor encourages attention to items' lexical attributes, and may therefore be expected to reduce the size of effects dependent on processing at this level. On the other hand, it has been reported that word-repetition effects, as assessed by a perceptual identification procedure, are uninfluenced by whether items are processed on initial presentation in the context of a physical or semantic task (Jacoby \& Dallas, 1981). One interpretation of this finding is that the type of encoding required for the occurrence of these effects is relatively automatic, in which case differences resulting from legal and illegal nonword repetition should still be present even when these items are presented in the context of a task emphasizing the processing of physical features.

\section{EXPERIMENT 2}

\section{Method}

Subjects. The subjects consisted of 12 young adults, none of whom had participated in Experiment 1. Five were female and all had normal or corrected-to-normal vision.

Stimuli. The same stimuli as in Experiment 1 were employed, with the exception of the target items. The words employed in the previous experiment were replaced by a new set of 80 legal and illegal nonwords, 40 of each type. In each of these, a randomly chosen letter was replaced by the character $@$, and these items were inserted randomly in the serial positions occupied by the target words in the lists employed in Experiment 1. Methods and parameters of stimulus presentation were identical to those employed in Experiment 1 except that exposure duration was increased from 161 to 200 msec.

Procedure and ERP recording. The experimental procedure and method of ERP recording were identical to those employed in Experiment 1 , except that the subjects' task was to maintain a count of those items containing the @ character.

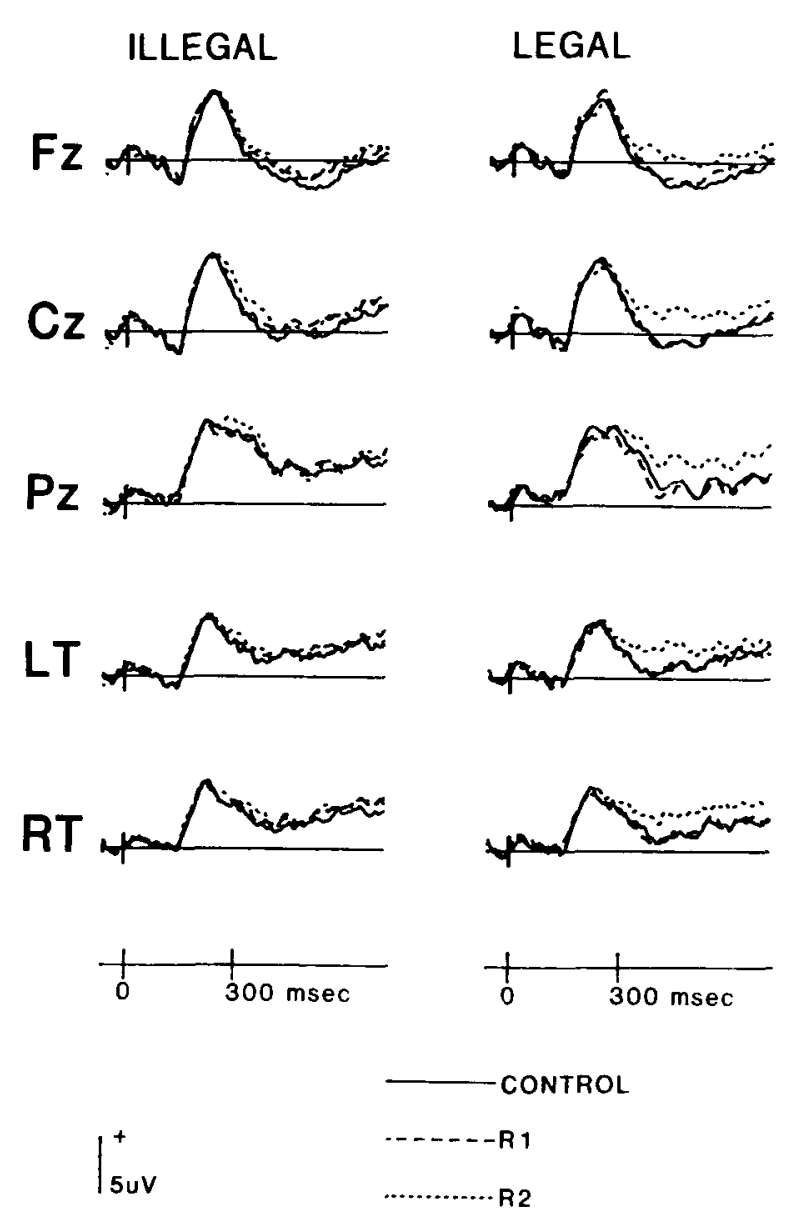

Figure 2. Grand average waveforms from Experiment 2, elicited by control, R1, and R2 orthographically illegal and legal nonwords. Electrode placements as for Figure 1.

\section{Results}

Grand average waveforms are shown in Figure 2. They are based on waveforms averaged over a mean of 48 trials per condition per subject (range: 40-50). Although they have the same general morphology as those from Experiment 1 , the effects of repetition are smaller in magnitude and appear confined to the ERPs elicited by the legal items. The waveforms were analyzed in the same way as in the previous experiment.

Analysis of the region of the waveform encompassing the $P 2$ peak (201-225 msec) gave rise only to a significant effect of site $[F(2.8,30.7)=6.2, p<.005$, MSe $=8.06]$, reflecting, as in the previous experiment, the midline predominance of this measure. The mean amplitude of the 228-297, 300-399, and 402-600 msec latency regions are shown in Table 3 . Analysis of the first of these regions gave rise only to an effect of site $[F(2,21.7)$, $p<.025, M S e=12.92$ ]. Planned comparisons between first and second presentations of legal and illegal items were, in each case, nonsignificant $[F(1,15)<1$, and $F(1,15)<1.97$, respectively, $M S e=5.88]$. Analysis of 
Table 3

Mean Amplitude (Microvolts) Across Electrode Sites of the 228-297, 300-399, and 402-600 msec Regions of the Waveforms in Experiment 2

\begin{tabular}{clcccc}
\hline Region & Items & Control & R1 & R2 & R2-R1 \\
\hline $228-297 \mathrm{msec}$ & Legal & 5.00 & 5.00 & 5.16 & 0.16 \\
& Illegal & 5.12 & 5.07 & 5.69 & 0.62 \\
$300-399 \mathrm{msec}$ & Legal & 1.78 & 1.58 & 3.31 & $1.73^{*}$ \\
& Illegal & 2.22 & 2.51 & 3.26 & 0.75 \\
$402-600 \mathrm{msec}$ & Legal & 0.57 & 0.62 & 2.57 & $1.95^{*}$ \\
& Illegal & 1.15 & 1.80 & 1.64 & -0.16 \\
\hline
\end{tabular}

${ }^{*} p<.01$

the 300-399 msec region revealed significant effects of site $[F(2.4,26.9)=13.79, p<.0001, M S e=14.93]$ and condition $[F(1.9,20.6)=9.44, p=.001, M S e=6.81]$. Planned comparisons indicated that although the difference between the R1 and $R 2$ conditions was significant for the legal items $[F(1,20.6)=13.32]$, it was not for the illegal nonwords $[F(1,20.6)=2.52]$. A similar pattern of results was obtained for the $402-600 \mathrm{msec}$ data, with significant effects of site $[F(2.6,28.1)=16.28$, $p<.0001, M S \mathrm{e}=12.27]$ and condition $[F(2,21.7)=$ $6.47, p<.01, M S e=7.65]$. As in the case of the previous measure, the $R 1 / R 2$ comparisons indicated a significant repetition effect for the legal $[F(1,21.7)=14.91]$, but not the illegal, items $(F<1)$. In view of the differences found in the 300-399 and 402-600 msec data of Experiment 1 between legal and illegal items in the control and R1 conditions, planned comparisons were also performed between these classes of item in the same conditions of the present study. In both latency regions, these contrasts were nonsignificant for control and R1 items $[F(1,11)<1$ and $F(1,11)<2.45$, respectively, $M S \mathrm{Se}=$ 10.58 for the $300-399 \mathrm{msec}$ measure; $F(1,11)<1$ and $F(1,11)<2.67, M S \mathrm{e}=15.46$ for the $402-600 \mathrm{msec}$ region].

The subjects counted on average $77(S D=4.4)$ of the 80 targets over the course of the experiment.

\section{GENERAL DISCUSSION}

The results of Experiment 2 are consistent with those of Experiment 1. Although the experimental task involved an analysis of surface features of the nonwords, and did not require lexical processing, ERP repetition effects were reliable only in the case of the legal items. This finding would appear to support the idea that these effects are largely confined to items that are capable of giving rise to significant activation within the lexical system.

A number of differences between the pattern of results in Experiments 1 and 2 should be noted. First, the differences observed in Experiment 1 between the legal and illegal items in the R1 and control conditions were not present to a significant extent in Experiment 2. Therefore, these may indeed have reflected the differential processing allocated to the two classes of item in Experiment 1 as a result of the need to conduct a lexical search only in the case of the legal items. Although this asymmetry in depth of processing may have contributed to the difference between the legal and illegal repetition effects observed in Experiment 1 , the results from Experiment 2 suggest that it is unlikely to be a necessary condition for its manifestation. The same holds true with respect to the possible inequality in the subjective probabilities of legal and illegal items in Experiment 1. Its elimination in Experiment 2 gave rise to even clearer differences between the effects of repeating these two types of nonword.

A second difference between the two experiments concerns the presence in Experiment 1, and the absence in Experiment 2, of repetition effects in the ERPs from illegal items. In Experiment 1 these began earlier in time with illegal than with legal items, and were of comparable magnitude in the 300-399 msec latency range. The differences in favor of the legal items did not emerge until later in the waveform. Presumably, this difference between these patterns of results in the two experiments is due to their differing task demands, and might reflect an episodic contribution to the processing of repetitions in Experiment 1, and the relative automaticity of some lexically based component of the processing of legal nonwords in Experiment 2. Alternatively, the effects in Experiment 1 might of course be attributable to the relative subjective rarity of illegal items. Either way, the existence of this reliable repetition effect for the illegal items in Experiment 1 indicates that detection of repetition of these items did in fact occur at some level, and that it is not the case that the subjects simply failed to remember the identity of illegal items from trial to trial. Indeed, Fowler, Napps, and Feldman (1985, Experiment 1) reported essentially equivalent degrees of facilitation (in a lexical decision task) in reaction times to repeated legal and illegal nonwords. This suggests that the aspects of the ERP repetition effects that are common to both classes of item in Experiment 1 may reflect processes that can exert an influence on time-locked behavior. The question of the functional relevance of the (putatively lexically based) processes reflected by the aspects of the ERP data that did discrimiante between repeated legal and illegal nonwords awaits further research on the effects on behavioral variables of these manipulations.

In neither of the current experiments was there any evidence for reliable effects of repetition on the region of the ERPs around the P2 component. This contrasts with previous work (Rugg, 1987) in which a suppression of the $\mathrm{P} 2$ peak of the ERP was observed in response to immediate repetitions of both words and nonwords. It is not clear why this finding was not replicated in the present experiments; the only obvious possibility concerns differences in the probability of a repetition between the two experiments, which was twice as large in the present case (.25) as in the study of Rugg (1987).

The question arises as to how the ERP repetition effects observed in this and in Rugg's (1987) study should be interpreted from the standpoint of other work on the modulation of late ERP components by cognitive variables. It is possible that the positive-going shift observed in ERPs to repeated stimuli is generated by the same 
processes as those responsible for the $\mathrm{P} 3$ component in other paradigms. Consistent with this idea is the fact that in the current experiments, repetition is a relatively rare event, and the inverse relationship between $\mathrm{P} 3$ amplitude and event probability is well known (e.g., DuncanJohnson \& Donchin, 1977). There are, however, at least two difficulties with this interpretation. First, the "classical" P3 has a parietal maximum, with an amplitude that falls off relatively rapidly over more anterior scalp regions. This contrasts with the repetition-sensitive ERP effects, which are diffusely distributed over the scalp. If the effects of repetition were due to the modulation of a parietally distributed component, they would be expected to show the same scalp distribution as that component. This would have shown up in the ERP analyses as an interaction with electrode site, indicating greater effects at $\mathrm{Pz}$ than at more anterior electrodes. In fact, none of the effects of repetition in these experiments was found to vary as a function of electrode site. Second, the relative improbability of a repeated item cannot be sufficient to give rise to ERP repetition effects; the legal and illegal nonwords were, at least in Experiment 2, matched in this respect. An alternative view of these ERP effects is to conceive of them as reflecting the action of one or more of the generators responsible for the late negative components, such as $\mathrm{N} 400$, that are observed in other language tasks. As noted in the introduction, it has frequently been observed, in a range of paradigms, that what might loosely be called unprimed words exhibit an enhanced late negativity in comparison to primed items (e.g., Bentin et al., 1985; Kutas \& Hillyard, 1984; Kutas \& Van Petten, 1987; Rugg, 1985). It is therefore possible that the positive-going modulation of ERPs to repeated items to some degree reflects the attenuation of a negativity generated as a consequence of the unprimed status of control and R1 items. Exacily what various priming manipulations have in common that they should modulate ERPs in this way, and. indeed, how such a conjecture can be tested, are questivi:s for the future.

Irrespective of the issues raised in the previous paragraph, the results from the present experiments seem clear. The moduluw $n$ of ERPs by the repetition of nonwords is highly sensitive to these items' orthographic structure. Nonwords with word-like orthographic characteristics, which presumably gain access to and activate representations in lexical memory, give rise to greater degrees of modulation than those observed with orthographically illegal letter strings (which are presumed not to gain access to lexical memory). This is inconsistent with the idea that the effects of repetition, even over short time intervals, can be understood entirely in terms of the formation and retrieval of episodic memories of items' prior occurrences.

\section{REFERENCES}

Bentin, S., McCARThy, G., \& Wood, C. C. (1985). Event-related potentials, lexical decision and semantic priming. Electroencephalography \& Clinical Neurophysiology, 60, 343-355.
Coles, M. G. H., Gratton, G., Bashore, T. R., Eriksen, C. W., \& Donchin, E. (1985). A psychophysiological investigation of the continuous flow model of human information processing. Journal of Experimental Psychology: Human Perception \& Performance, 11, 529-553.

Courchesne, E., Hillyard, S. A., \& Courchesne, R. Y. (1977). P3 waves to the discrimination of targets in homogeneous and heterogeneous stimulus sequences. Psychophysiology, 14, 590-597.

Dannenbring, G. L., \& Briand, K. (1982). Semantic priming and the word repetition effect in a lexical decision task. Canadian Journal of Psychology, 36, 435-444.

Den Heyer, K., Goring, A., \& Dannenbring, G. L. (1985). Semantic priming and word repetition: The two effects are additive. Joumal of Memory \& Language, 24, 699-716.

Duncan-Johnson, C. C., \& Donchin, E. (1977). On quantifying surprise: The variation of event-related potentials with subjective probability. Psychophysiology, 14, 456-467.

Evett, L. J., \& Humphreys, G. W. (1981). The use of abstract graphemic information in lexical access. Quarterly Journal of Experimental Psychology, 33A, 325-350.

Feustel, T. C., Shiffrin, R. M., \& Salasoo, A. (1983). Episodic and lexical contributions to the repetition effect in word identification. Journal of Experimental Psychology: General, 112, 309-346.

Forbach, G. B., Stanners, R. F., \& Hochiaus, L. (1974). Repetition and practice effects in a lexical decision task. Memory \& Cognition, 2, 337-339.

Fowler, C. A., NapPs, S. E., \& Feldman, L. (1985). Relations among regular and irregular morphologically related words in the lexicon as revealed by repetition priming. Memory \& Cognition, 13, 241-255.

Hillyard, S. A., \& Kutas, M. (1983). Electrophysiology of cognitive processing. Annual Review of Psychology, 34, 33-61.

JaCOBY, L. L. (1983). Perceptual enhancement: Persistent effects of an experience. Journal of Experimental Psychology: Learning, Memory, \& Cognition, 9, 21-38.

JACOBY, L. L., \& DaLlaS, M. (1981). On the relationship between autobiographical memory and perceptual learning. Joumal of Experimental Psychology: General, 110, 306-340.

Johnston, W. A., Dark, V. J., \& Jacoby, L. L. (1985). Perceptual fluency and recognition judgments. Joumal of Experimental Psychology: Learning, Memory, \& Cognition, 11, 3-11.

KAY, J. (1985). Mechanisms of oral reading: A critical appraisal of cog nitive models. In A. W. Ellis (Ed.), Progress in the psychology of language (Vol. 2). London: Erlbaum.

Keselman, H. J., \& Rogan, J. C. (1980). Repeated measures F tests and psychophysiological research: Controlling the number of false positives. Psychophysiology, 17, 499-503.

KuTAS, M., \& Hillyard, S. A. (1980). Reading senseless sentences: Brain potentials reflect semantic incongruity. Science, 207, 203-205.

KUTAS, M., \& HillyARD, S. A. (1983). Event-related brain potentials to grammatical errors and semantic anomalies. Memory \& Cognition, $11,539-550$

Kutas, M., \& Hillyard, S. A. (1984). Brain potentials during reading reflect word expectancy and semantic association. Nature, 307, 161-163.

Kutas, M., \& Van Petten, C. (1987). ERP studies of language. In P. K. Ackles, J. R. Jennings, \& M. G. H. Coles (Eds.), Advances in psychophysiology. Greenwich, CT: JAI Press.

MoNSELL, S. (1985). Repetition and the lexicon. In A. W. Ellis (Ed.), Progress in the psychology of language (Vol. 2). London: Erlbaum. MoRTON, J. (1969). Interaction of information in word recognition. Psychological Review, 76, 165-178.

MoRTON, J. (1979). Facilitation in word recognition: Experiments causing change in the logogen model. In P. A. Kolers, M. E. Wrolstad, \& M. Bound (Eds.), Processing of visible language. New York: Plenum Press.

MuRRell, G. A., \& Morton, J. (1974). Word recognition and morphemic structure. Journal of Experimental Psychology, 102, 963-968.

Picton, T. W. (1980). The use of human event-related potentials in psychology. In I. Martin \& P. H. Venables (Eds.), Techniques in psychophysiology. Chichester: Wiley. 
Pritchard, W. S. (1981). Psychophysiology of P300. Psychological Bulletin, 89, 506-540.

RuGG, M. D. (1985). The effects of semantic priming and word repetition on event-related potentials. Psychophysiology, 22, 642-647.

RUGG, M. D. (1987). Dissociation of semantic priming, word and nonword repetition by event-related potentials. Quarterly Journal of Experimental Psychology, 39A, 123-148.

RUGG, M. D., KoK, A., BARRETT, G., \& Fischler, I. (1986). ERPs associated with language and hemispheric specialization. In W. C. McCallum, R. Zappoli, \& F. Denoth (Eds.), Cognitive psychophysiology: Studies in ERPs. Amsterdam: Elsevier.

Salasoo, A., Shiffrin, R. M., \& Feustel, T. C. (1985). Building permanent memory codes: Codification and repetition effects in word identification. Journal of Experimental Psychology: General, 114, 50-77.

Scarborough, D. L., Cortese, C., \& Scarborough, H. S. (1977). Frequency and repetition effects in lexical memory. Journal of Experimental Psychology: Human Perception \& Performance, 3, 1-17.
WILDING, J. (1986). Joint effects of semantic priming and repetition in a lexical decision task: Implications for a model of lexical access. Quarterly Journal of Experimental Psychology, 38A, 213-228.

\section{NOTE}

1. Amplitude measures from each latency region in Experiments 1 and 2 were also subjected to additional analyses including data from only the two temporal electrodes, to maximize the probability of detecting any lateral asymmetries that might exist. In no case did the two electrode sites differ reliably as a function of an experimental manipulation.
(Manuscript received July 24, 1986; revision accepted for publication January $20,1987$. ) 